\title{
A new practical teaching system to cultivate application-oriented innovative talents majoring in materials science and engineering
}

\author{
C. Q. Zhang, L. Shi, Q. L. Sun \& K. G. Liu \\ School of Materials Science and Engineering, Shandong Jianzhu University, China
}

Keywords: talent training mode; curriculum system; practical teaching system; innovative talents

\begin{abstract}
Materials and the related manufacturing industry involve every area of the economy, and the corresponding talent demand ranks in the forefront of all industry professionals. However, the defects of current talent training mode and curriculum system limit the quality of talent training. In this paper, we proposed some measures to reform the talent training mode, and meanwhile optimized the current curriculum system. On this basis, a new practical teaching system was designed to cultivate innovative talents of broad caliber, solid foundation, strong capacity and high quality that were engaged in various related fields. According to the feedback from employers, our new practical teaching system could well meet the needs of enterprises on application-oriented innovative talents.
\end{abstract}

\section{Introduction}

As the pillar industry of national economy, materials and the related manufacturing industry involve every area of the economy, and play a decisive role in the progress of human civilization and social development. Consequently, the corresponding talent demand has ranked in the forefront of all industry professionals over the past decades. Recently, Chinese government has formulated a series of policies to promote the update of traditional manufacturing, among which Shandong Peninsula Blue Economic Zone and the Yellow River Delta Efficient Ecological Economic Zone are two national strategies that aim to further enhance the competitiveness of Shandong province. Obviously, the implementation of these two strategies has undoubtedly brought great opportunities for regional economic development of Shandong province [1]. According to the survey on college graduates in Shandong province in recent years, a large number of graduates who major in materials science and engineering are needed for Shandong local economic development, especially the talents equipped with good practical ability and technical innovation.

The major of materials science and engineering in Shandong Jianzhu University aims to cultivating innovative talents of broad caliber, solid foundation, strong capacity and high quality. In terms of teaching theory, we firstly implement a fair and impartial examination and assessment system to encourage the enthusiasm and initiative of students, and further compile a set of textbooks that are suitable to engineering colleges majoring in materials science and engineering to meet the teaching requirements of different major orientations. Meanwhile, we pay enough attention to the laboratory construction and experimental teaching reformation, and make great efforts to change the traditional philosophy that experimental teaching must attach to theoretical teaching. However, the original curriculum system and course content can not meet the requirements of industry development, and there is a gap between the comprehensive practical ability of our graduates and industry development. In this paper, we design a new practical teaching system to cultivate application-oriented innovative talents that are engaged in new building materials, material corrosion and protection, material analysis and testing, material heat treatment, etc. We believe that this new practical teaching system can help to build the major of materials science and engineering in Shandong Jianzhu University into a well-known and impactful undergraduate major in the fields of construction, machinery and chemical industry in Shandong province and even China.

\section{Reformation of talent training mode}

In order to optimize current talent training mode, we conduct a long-term investigation on the 
needs of employers from large and medium-size enterprises and famous institutes. Combined with the professional characteristics, we improve the order-oriented training mode, and constitute a new talent training scheme, together with the corresponding professional standards [2, 3]. Furthermore, we analyze the employer requirements, and strengthen the implementation of excellent engineer training program [4]. As a result, the talent training mode reform has achieved a significant effect, and a common evaluation mechanism on talent training is gradually forming.

\subsection{General talent training mode}

We firstly adopt a general training mode to make the students possess the fundamental professional quality, and then progressively execute a special training mode to offer the students unique practical skills. Based on the objective of cultivating applied talents, we integrate three aspects of talent training including basic theory study, practical ability enhancement and overall quality improvement, and finally realize the comprehensive development of students.

For the first three semesters, basic education and humanity education are highlighted based on the platform of general education courses. On this basis, basic practical ability training is strengthened to improve the basic practical ability of students. In this phase, ideological and political education and social practice are the focuses of education, and the ideological and moral cultivation of students can be enhanced to a large extent.

For the middle three semesters, professional basic education is the core of theoretical teaching. Meanwhile, the professional practical ability of students should be cultivated through professional practice. Further, relying on the second classroom practical education, the innovative spirit and practical ability of students can be enhanced simultaneously.

For the last two semesters, the professional knowledge of students can be further enlarged relying on the platform of kernel specialized courses. Meanwhile, by virtue of comprehensive practice, engineering practice ability and professional quality of the students can be enhanced. Combined with necessary innovation education and employment guidance, the employability, innovation and entrepreneurship of students can be comprehensively improved.

\subsection{Order-oriented training mode based on school-enterprise cooperation}

We establish solid cooperative relations with Yantai Construction Group, China National Heavy Duty Truck Group, Shandong Jianze Concrete Co. Ltd., and Jinan Giant Tower Co. Ltd., and develop a regular communication mechanism with these enterprises. Thus, the scale of order-oriented talent cultivation is increasingly expanded, and the annual number of graduates to these enterprises can be increased from the current 80 or so to more than 100 . In addition, we collaborate with Jin Jing Group in manufacturing architectural glasses such as low-emissivity coated glass and solar glass, and expand the professional fields of "Order-oriented" training, which not only promotes the development of green building industry but also cultivates plentiful applied innovative talents for the construction industry of Shandong province.

\section{Optimization of the curriculum system}

According to the development and requirements of national economy and the related industries, the construction of curriculum system, teaching content, teaching methods and other aspects must be continuously strengthened. Considering the professional characteristics of construction material engineering, material surface engineering and material heat treatment, a curriculum system with reasonable structure and distinctive characteristics should be built to cultivate the engineering practice ability, innovation and scientific research capability of students. Accordingly, the curriculum provision can be divided into three levels, including general education, engineering basic education, engineering professional education.

It is noticed that the construction and reformation of curriculum system and teaching content should always reflect the development characteristics of the corresponding industry, and thus keep the same pace with the development of related industries. For example, we develop two courses of low-emissivity coated glass and solar glass jointly with Jin Jing Group; we enrich the teaching content of engineering training through deep cooperation with China National Heavy Duty Truck Group and other enterprises. By this way, new knowledge and new technologies can be 
supplemented timely into original teaching content, thus further improving the teaching quality.

Considering the professional characteristics of construction material engineering, material surface engineering and material heat treatment, we build a curriculum system with reasonable structure and distinctive characteristics to cultivate the engineering practice ability, innovation and scientific research capabilities of students. Thus, taking the engineering and technology as main line, the engineering awareness, engineering quality and engineering practice ability can be improved significantly. Accordingly, the curriculum provision is divided into three levels, including general education, engineering basic education, engineering professional education, as shown in Figure 1.

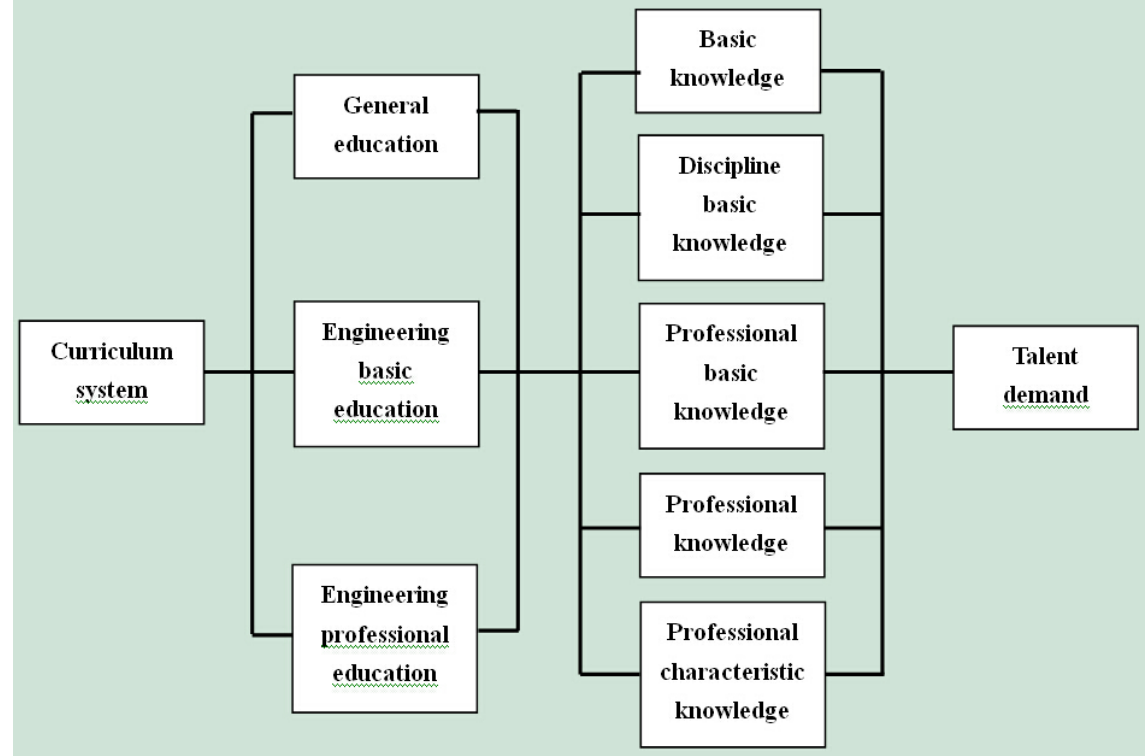

Figure 1: Curriculum system of the major of materials science and engineering.

\section{Design of the practical teaching system}

The practical teaching mode should be optimized based on the orientation and requirements of application-oriented talents [5-7]. For students of different major orientations in the same field, we set up the same basic practice courses, but different professional practice courses. Meanwhile, according to the characteristics of different major orientations, we arrange different professional practice courses at different learning stages. Thus, the practical teaching can form a comprehensive system which consists of basic practical teaching, professional practical teaching, engineering practical teaching, innovation practical teaching and quality practical teaching, as shown in Figure 2.

Basic practical teaching mainly includes the experimental teaching and the curriculum design of basic courses, such as the metalworking practice of three weeks long and the curriculum design of two weeks long for "Fundamentals of mechanical design".

Professional practical teaching not only involves common contents that all major orientations must participate in, but also prepares different curriculum experiments and different curriculum designs for different major orientations. For example, with regard to the orientation of construction materials, we set up a curriculum experiment of three weeks long for "Construction structural materials", and a curriculum design of two weeks long for "Construction engineering material budget". In order to ensure the quality and effectiveness of the experiments, we develop standardized experimental guide books and experimental reports, so that the experiment contents can really meet the requirements of comprehensive experiments and contrivable experiments.

Engineering practical teaching includes cognition practice, production practice, graduation practice and professional reports or lectures of enterprise experts. During the construction of this module, on the one hand, we actively improve the infrastructure and innovation conditions of current practice bases in Jinan, Yantai and Luoyang, and meanwhile try to build new practice bases in developed regions such as Shanghai and Beijing; on the other hand, we strive to establish long-term and stable training bases closely related to our major orientations in these cooperative 
enterprises, so that the students can receive targeted, systematic, and standardized skill training according to the teaching program requirements. As a consequence, their professional practical ability can be greatly enhanced, and finally achieves the desired training objectives.

In order to cultivate the innovation spirit and practical ability, we schedule various innovative activities including open experiment plan, research proposal project, special interest group and patent application training in the innovation practical teaching module; meanwhile, we encourage and guide the students to participate in various technological and professional competitions.

Quality practical teaching mainly includes summer social practice and skill training. This module can make the students familiar with occupational characteristics, so that they can acclimatize themselves to work even faster after graduation.

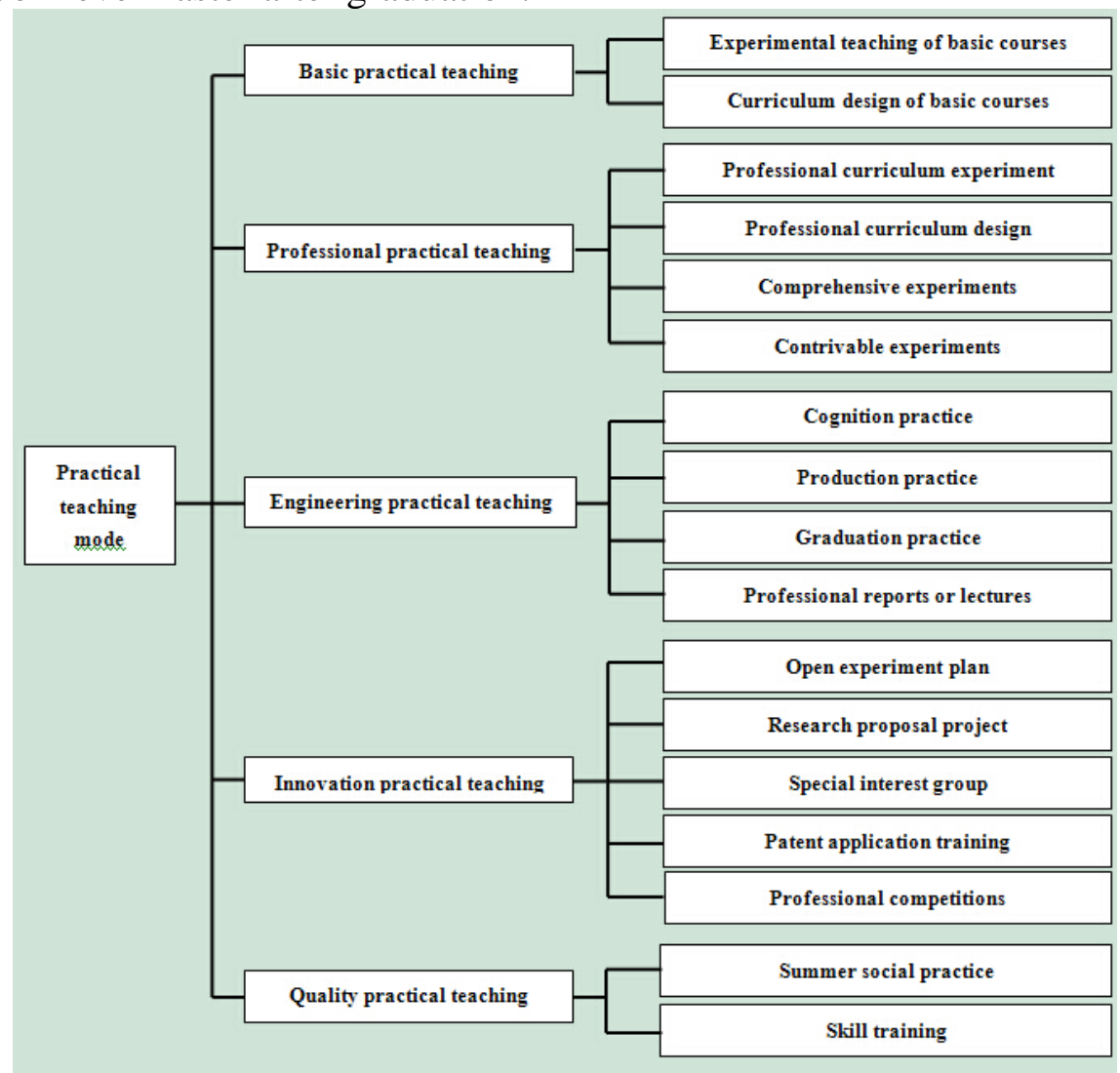

Figure 2: Schematic of the practical teaching system.

\section{Conclusions}

By designing new talent training mode and optimizing curriculum system, we developed a new practical teaching mode which took the first classroom as the main line and the students' social practice, skill training, technological innovation, academic competitions, and other extra-curricular activities as the assistant line. Through this practical teaching mode, the interest of students in self-learning, and self-training could be effectively motivated, which ensured the effective operation of the practical teaching system. According to the feedback from employers, compared with the past graduates and graduates of other schools, the graduates of recent three years, who received the training of the new practical teaching mode, had significantly enhanced practical ability, and could adapt to their posts of duty more rapidly. That is to say, our new practical teaching system can well meet the needs of enterprises on application-oriented innovative talents.

\section{References}

[1] Wang, X. J., Qi, Z. F. \& Guo, J., A study on development of manufacturing industry clusters in Jiaodong Peninsula. East China Economic Management, 2014(1), pp. 26-29. 
[2] Wang, Y., Zhao, L. L. \& Guo, X. F., Training status and cultivation approaches of double-qualified teachers in engineering universities. Advanced Materials Research, 785-786, pp. 1489-1492, 2013.

[3] Luo, G. S. \& Li, X. G., Exploration and practice of talent training under order-oriented mode. Occupation, 2009(26), pp.143-144.

[4] Niu, J. Y., Guo, S. B. \& Xu, F. W., Exploration on talent training mode of local engineering colleges under excellent engineering plan. Education Science \& Culture Magazine, 2014(12), pp. 59-60.

[5] Bai, J. S., Reformation and practice of practical teaching in higher engineering colleges. Course Education Research, 2014(27), pp. 31-31.

[6] Chen, F. X., Guo, J. Q., Cheng G. Y. \& Qiu, R. F., Innovation and practice of practical teaching system in the major of materials in engineering colleges. China Education Innovation Herald, 2014(10), pp. 10-11.

[7] Yu, H. L., Bi, G. \& Gao, Y. B., Cultivating practical ability and innovation awareness of students through integrated practical teaching system. Laboratory Science, 2010(6), pp. 3-6. 